\title{
DEVELOPMENT, ASSESSMENT AND VERIFICATION OF FINITE ELEMENT PROCEDURES FOR CONTACT PROBLEMS
}

\author{
D. Gabriel * , J. Kopačka*, J. Masák* , J. Plešek*
}

\begin{abstract}
A frictionless three-dimensional contact algorithm based on the pre-discretization penalty formulation was proposed. The algorithm proved to be robust, accurate and symmetry preserving-no master/slave surfaces have been introduced. It was implemented in the finite element code PMD (Package for Machine Design) for the solution of complex engineering problems. The capability of the algorithm was demonstrated in creep analysis of T-piece of the steam distributor of the CHEMOPETROL heating plant T200. Material properties were described by the probabilistic exponential model with damage. The purpose of the analysis was to compare the original version and the proposed design modification applied to one of T-pieces of the distributor when the proposed contact algorithm was employed to simulate the interaction between the collar and the pipe.
\end{abstract}

Keywords: FEM, contact algorithm, creep analysis, T-piece of the steam distributor

\section{Introduction}

In the context of the finite element method, a frictionless three-dimensional contact algorithm using prediscretization penalty formulation was proposed, see (Gabriel et al., 2004). The key feature of this algorithm is that the local search and the penalty constraint enforcement are performed on the Gausspoint level of quadratic serendipity elements rather than the nodal level of a finite element mesh. The method was shown to be consistent with the variational formulation of a continuum problem, which enables incorporation of higher-order elements with midside nodes to the analysis. Owing to a careful description of kinematics of contacting bodies when the non-linearized definition of penetration has been introduced, the displacement increments in the course of one load step were permitted to be large. Thus, the extension to geometrically nonlinear problems was straightforward. The algorithm proved to be robust, accurate and symmetry preserving - no master/slave surfaces have been introduced. It was implemented in the finite element code PMD-(Package for Machine Design, 2013) for the solution of complex engineering problems.

In this work, the capability of the contact algorithm was demonstrated in creep analysis of T-piece of the steam distributor, which is part of the CHEMOPETROL heating plant T200, see (Bielak et al., 2001). The distributor, which consists of series of T-pieces, was subjected to the thermal load of steam $510\left[{ }^{\circ} \mathrm{C}\right]$. During several thousand hours of operation under creep conditions permanent deformation and damage occurred near to the welded joints of pipes. In order to eliminate this effect a bracing collar welded on the transient area of pipes was designed. The purpose of the analysis was to compare the original version and the proposed design modification applied to one of T-pieces of the distributor when the proposed contact algorithm was employed to simulate the interaction between the collar and the pipe.

\section{Complex probabilistic exponential model with damage}

Material creep properties were described by complex probabilistic exponential model with damage developed by Bina and Hakl (1994). The governing equation furnishing the dependence of the total strain $\epsilon_{c}$ on

Ing. Dušan Gabriel, Ph.D., Ing. Ján Kopačka, Ph.D., Ing. Jan Masák, Ing. Jiří Plešek, CSc.: Institute of Thermomechanics of the CAS, v. v. i.; Dolejškova 1402/5; 182 00, Praha 8; CZ, \{gabriel, kopacka, masak, plesek\} @it.cas.cz 
initial strain $\epsilon_{0}$, limit strain $\epsilon_{m}$ and damage $\pi(t)$ at time $t$ is

$$
\epsilon_{c}\left(\sigma_{e}, T, t\right)=\epsilon_{0}\left(\frac{\epsilon_{m}}{\epsilon_{0}}\right)^{g[\pi(t)]}
$$

where $\sigma_{e}$ is the effective stress in [MPa], $T$ is the thermodynamic temperature in [K], $t$ the time in [hours]. The initial strain $\epsilon_{0}$ can be calculated from the elastic solution

$$
\epsilon_{0}=100 \frac{\sigma_{e}}{E(T)}
$$

where the dependence of the Young modulus on temperature is supposed to have the form

$$
E(T)=E_{1}+E_{2} \exp ^{-\left(E_{3} / T\right)}
$$

The limit strain $\epsilon_{m}$ can be expressed by

$$
\epsilon_{m}=\exp \left[M_{1}+M_{2} \tanh \left(\frac{\ln \left(t_{r}\right)-M_{3}-M_{4} T}{M_{5}}\right)\right]+100 \frac{\sigma_{e}}{E(T)}
$$

The damage parameter $\pi(t)$ is defined as

$$
\pi(t)=\frac{t}{t_{r}} \in(0,1)
$$

where $t_{r}$ is the time elapsed at rupture in [hours], estimated by the empiric formula

$$
\begin{aligned}
\log t_{r} & =A_{1}+A_{2} \log \left|\frac{1}{T}-\frac{1}{A_{5}}\right|+A_{3} \log \left|\frac{1}{T}-\frac{1}{A_{5}}\right| \log \left(\sinh \left(A_{6} \sigma_{e} T\right)\right)+ \\
& +A_{4} \log \left(\sinh \left(A_{6} \sigma_{e} T\right)\right)
\end{aligned}
$$

The hardening function $g[\pi(t)]$ can be expressed as

$$
g[\pi(t)]=[\pi(t)]^{N}\left[\frac{1+\exp ^{-2 \pi^{K}(t)}}{1+\exp ^{-2}}\right]^{M}
$$

Material data are given by parameters for the initial strain $E_{1}-E_{3}$, rupture strain $M_{1}-M_{5}$, creep strength $A_{1}-A_{6}$ and hardening function $N, M, K$. Generalized constitutive equations for creep follow from the Prandtl-Reuss equations

where $S_{i j}$ is the deviatoric stress

$$
\dot{\epsilon}_{i j}^{c}=\frac{3}{2} \frac{\dot{\epsilon}_{c}}{\sigma_{e}} S_{i j}
$$

$$
S_{i j}=\sigma_{i j}-\frac{1}{3} \delta_{i j} \sigma_{k k}
$$

The effective stress $\sigma_{e}$ is given by von Mises' function

$$
\sigma_{e}=\sqrt{\frac{3}{2} S_{i j} S_{i j}}
$$

The effective creep strain $\epsilon_{c}$ can be expressed as

$$
\epsilon_{c}=\int_{0}^{t} \sqrt{\frac{2}{3} \dot{\epsilon}_{i j}^{c} \dot{\epsilon}_{i j}^{c}} \mathrm{~d} \tau
$$

assuming that the damage softening method is used

$$
\dot{\epsilon}_{c}=\phi\left(\pi, \sigma_{e}, T\right)
$$

Isotropic hardening function $\phi$ can be obtained from equations (1)-(7) by elimination of time $t$. Constitutive equations (8)-(12) are integrated by an original explicit algorithm for integration of differential systems arising from viscoplastic or creep finite element analyses, see (Plešek and Korouš, 2002). The algorithm combines Euler's forward scheme applied to discretised equilibrium equations at constant stress with a more precise procedure for the solution of local constitutive equations on the Gauss point level. Automatic subincrementation strategy ensures that the global error comprising both the truncation and roundoff errors remains bounded. The time step length is set on the basis of a posteriori error estimate. The robustness of the proposed procedure was tested by means of numerical examples, including benchmark problems introduced by Zienkiewicz and Cormeau (1974). 


\section{Finite element analysis}

The T-piece consists of pipes $\varnothing 377 \times 32[\mathrm{~mm}]$ and $\varnothing 219 \times 20[\mathrm{~mm}]$. By triple symmetry, one eighth of the branch was modelled using 2600 isoparametric pentahedral and hexahedral quadratic elements (Fig. 1). Over-pressure loading $p=7[\mathrm{MPa}]$ was applied. Material data of the complex probabilistic exponential model for the steel 15218.5 are given in (Bielak et al., 2001). The analysis was performed in the finite element system PMD.

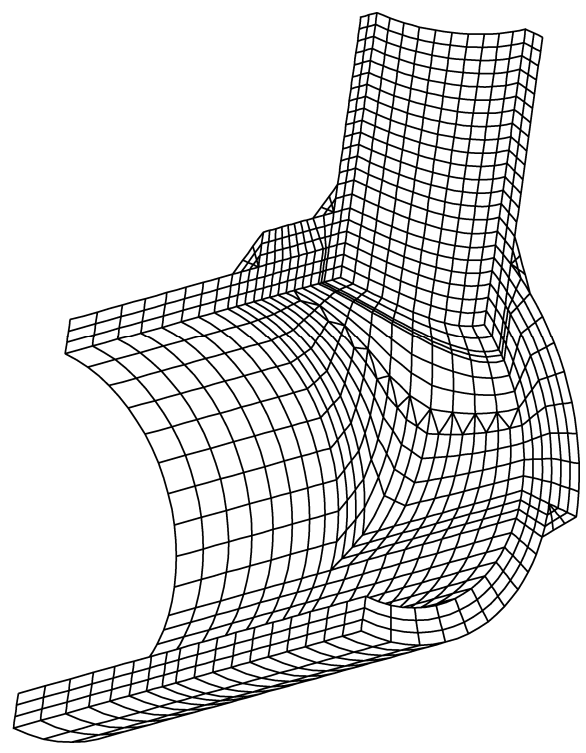

Fig. 1: Finite element model of T-piece with a bracing collar

The maximum values of the von Mises stress, effective creep strain $\epsilon_{c}$ and damage $\pi$ for original design and the proposed modification are summarized in Tab. 1 for selected times 0, 100, $1000,10000,30000$, $80000,120000,160000,200$ 000, 250000 [hours]. For illustration, the effective creep strain distributions in T-piece for both variants are plotted at time 250000 [hours] in Fig. 2.

Tab. 1: Maximum values of the von Mises stress, effective creep strain $\epsilon_{c}$ and damage $\pi$ for original version and proposed modification

\begin{tabular}{rcccccc}
\hline & \multicolumn{3}{c}{ original version } & \multicolumn{3}{c}{ proposed modification } \\
\hline$t$ [hours] & von Mises [MPa] & $\epsilon_{c}[-]$ & $\pi[-]$ & von Mises [MPa] & $\epsilon_{c}[-]$ & $\pi[-]$ \\
\hline \hline 0 & 156.67 & 0 & 0 & 101.99 & 0 & 0 \\
100 & 117.02 & 0.000747 & 0.00378 & 85.02 & 0.000180 & 0.000155 \\
1000 & 103.18 & 0.001340 & 0.01510 & 77.44 & 0.000306 & 0.000752 \\
10000 & 88.60 & 0.001870 & 0.02970 & 67.61 & 0.000545 & 0.003580 \\
30000 & 82.38 & 0.002670 & 0.05540 & 62.46 & 0.000742 & 0.007520 \\
80000 & 77.43 & 0.003150 & 0.07210 & 58.21 & 0.001000 & 0.014500 \\
120000 & 75.52 & 0.001320 & 0.02290 & 56.56 & 0.001150 & 0.019100 \\
160000 & 74.21 & 0.003590 & 0.08710 & 55.43 & 0.001270 & 0.023300 \\
200000 & 73.18 & 0.003980 & 0.10110 & 54.61 & 0.001380 & 0.027100 \\
250000 & 72.28 & 0.004450 & 0.11750 & 53.78 & 0.001510 & 0.031600 \\
\hline
\end{tabular}

\section{Conclusions}

In this work, the finite element analysis of the steam distributor of the CHEMOPETROL heating plant T200 was analyzed using proposed contact algorithm based on the pre-discretization penalty formulation. The capability of contact algorithm was demonstrated. Based on the results shown in Tab. 1 it is clear that the bracing collar significantly influences quantities such as the maximum values of the von Mises stress, effective creep strain $\epsilon_{c}$ and damage $\pi$. For time 250000 [hours] the results showed a drop of $26 \%, 66 \%$ 


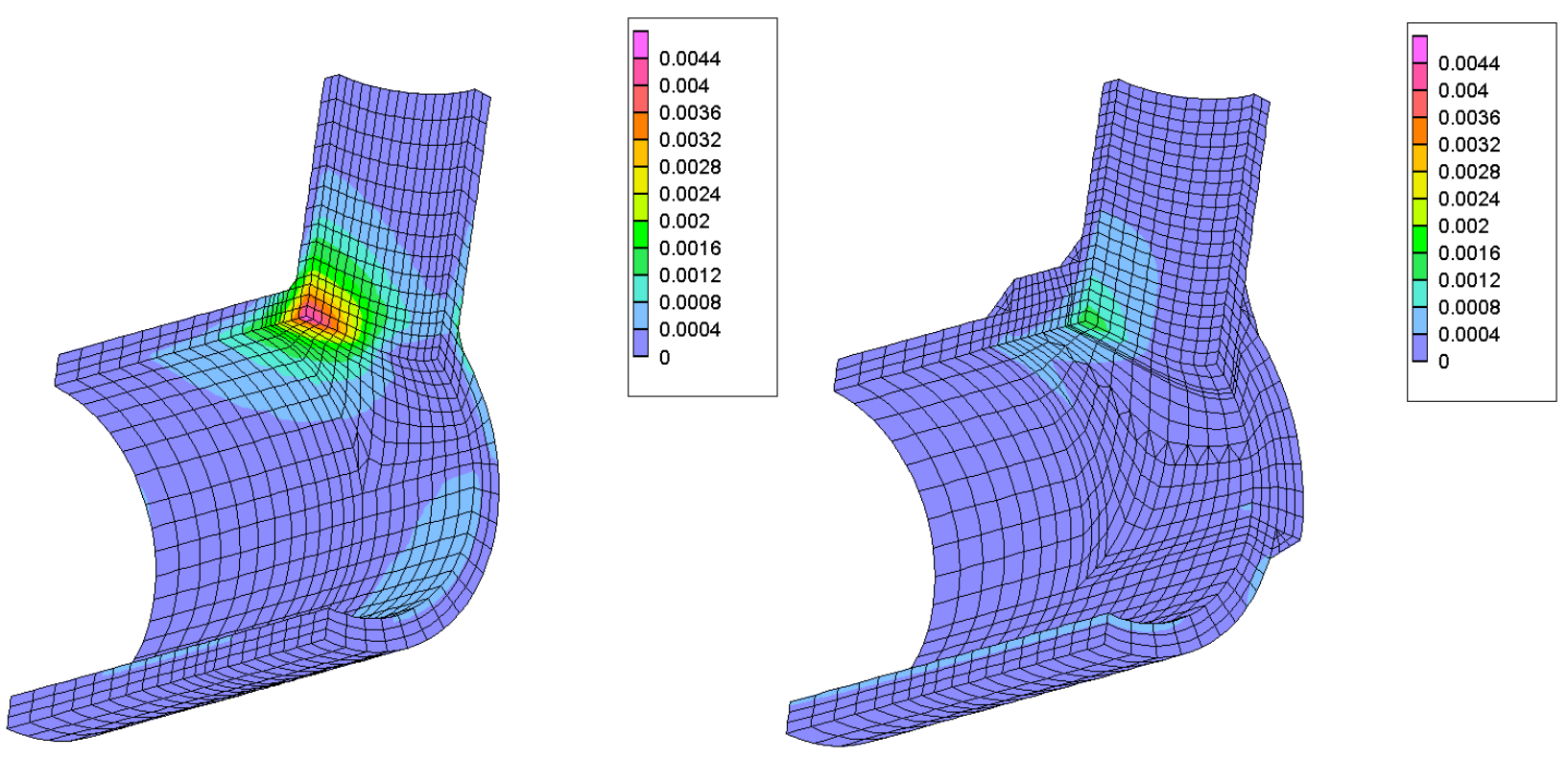

Fig. 2: Effective creep strain distribution in T-piece at time 250000 [hours]: original version (left) and proposed modification (right)

and $73 \%$ for the von Mises stress, effective creep strain and damage, respectively. It was concluded that the proposed constructional modification was desirable for the elimination of permanent creep deformation and damage.

\section{Acknowledgments}

The work of D. Gabriel, J. Kopačka and J. Plešek was supported by the European Regional Development Fund under Grant No. CZ.02.1.01/0.0/0.0/15_003/0000493 (Centre of Excellence for Nonlinear Dynamic Behaviour of Advanced Materials in Engineering) within institutional support RVO:61388998.

\section{References}

Bielak, O., Bína, V., Kanócz, A., Korouš, J. and Masák, J. (2001) Výpočet životnosti a zhodnocení provozní spolehlivosti rozdělovače páry C1-C2 teplárny T200, CHEMOPETROL a.s., zpráva Z-01-131, BiSAFE, s.r.o. (in Czech).

Bína, V. and Hakl, J. (1994) Probabilistic approach to description of the creep strain characteristic and prediction for long life-time. In Proc. Conf. Materials for Advanced Power Engineering, Coustouradis, D. et al. (eds), Kluwer Academic Publishers, Dordrecht (Boston), pp 601-610.

Gabriel, D., Plešek, J. and Ulbin, M. (2004) Symmetry preserving algorithm for large displacement frictionless contact by the pre-discretization penalty method. Int. J. Num. Met. Engng, Vol. 61, pp 2615-2638.

Package for Machine Design-PMD, version f77.11, VAMET/Institute of Thermomechanics, 2013, http://www.pmdfem.com/.

Plešek, J. and Korouš, J. (2002) Explicit integration method with time step control for viscoplasticity and creep. Advances in Engineering Software, Vol. 33, pp 621-630.

Zienkiewicz, O.C. and Cormeau, I. (1974) Visco-plasticity-plasticity and creep in elastic solids-a unified numerical approach. Int. J. Numer. Methods Engng., Vol. 8, pp 821-845. 